\title{
Effect of Flow Condition and Base Contact Ratio of Perforated Array Fins on Heat Transfer Augmentation using Computational Fluid Dynamics technique
}

\author{
Ankit Vyas ${ }^{1}$, Prof Sunil Gupta ${ }^{2}$, Prof Sandeep Gupta ${ }^{3}$ \\ ${ }^{1}\left(2^{\text {nd }}\right.$ Year. Thermal Engg. Jodhpur Institute of Engineering and Technology, India) \\ ${ }^{2}$ (Associate Prof. Dept. of Mechanical Engineering, Jodhpur Institute of Engineering and Technology, India) \\ ${ }^{3}$ (Assistant Prof. Dept. of Mechanical Engineering, Jodhpur Institute of Engineering and Technology, India)
}

\begin{abstract}
Heat dissipation is a major aspect in many applications involving thermal energy. Thermal performance can be enhanced considerably using fins. In this paper perforated fins with varying contact ratio with base plate are analyzed for the augmentation of heat transfer from the base plate. Comparison of Nusselt number with Reynold number has been done for various configurations of fins in this study.
\end{abstract}

Keywords: Ansys Fluent 13.0, base contact ratio, CFD and Finite Element Method, perforated fins.

\section{Introduction}

Rate of heat transfer from object can be increased by using fins. Fins are also called extended surfaces. The fins enhance the heat transfer rate from a surface by exposing larger surface area to convection. Since experimental analysis is costly heat transfer through fins can be analyzed through software like ansys. Computer simulation has become a useful part of modeling in engineering to gain insight into the operation of systems. Computational fluid dynamics applies numerical methods (called discretization) to develop approximations of the governing equations. Finite Element Analysis methodology and ANSYS 13.0 package is used for analysis. Much literature material is available for the different shape and size of fin analysis in different conditions but very less information is available for the analysis based on base contact ratio. Kavita H. Dhanawade, Vivek K. Sunnapwar and Hanamant S. Dhanawade (2014) experimentally investigated increase in heat transfer over horizontal flat surface with rectangular fin arrays, lateral square and circular perforation by forced convection. They compared the results obtained from rectangular fin with circular/square perforations with an equivalent rectangular solid fin and found that percentage improvement in temperature of square perforated fin arrays is more than fin arrays of circular perforated fin of same size $[1,2]$. B. V. S. S. S. Prasad \& A. V. S. S. K. S. Gupta (1998) suggested a method for reducing the weight of a straight rectangular fin by providing a semicircular cut at its tip [3]. U. Akyol and K. Bilen (2006) studied heat transfer and friction loss characteristics in horizontal rectangular channel having attachments of hollow rectangular profile fins. Two arrangements inline and staggered fin were studied for one fixed span wise, four different stream wise distances and correlation equations for Nusselt number and friction factor are determined [4]. N. Souidi, A. Bontemps (2001) worked on counter current gas liquid flow in narrow rectangular channels simulated by plain fins and perforated fins [5]. Abdulla H.M, AlEssa (2008) worked on heat transfer dissipation from horizontal rectangular fin embedded with triangular perforations numerically using finite element technique [6]. Heat dissipation rate of solid fin and perforated fin are calculated and compared. D. Abdullah H. AlEssa (2012) studied increase in natural convection heat transfer from a rectangular fin with rectangular perforations. Results obtained shows that for different dimensions of rectangular perforations there is an increase in heat dissipation of perforated fin over that of identical solid fin with the increase in perforations [7]. A.H. AlEssa et al, $\mathbf{( 2 0 0 8 , 2 0 0 9 )}$ studied increase in natural convection heat transfer from a horizontal rectangular fin embedded with rectangular perforations of aspect ratio of two with the help of finite element technique. Results obtained by comparing a perforated fin with an identical solid fin, by examining gain in fin area and of heat transfer coefficients due to perforations which are used to judge the influence of fin and perforation factors on increase in heat transfer rate. It is found that heat transfer coefficient of fin surface can be increased by introducing surface roughness and therefore promoting turbulence $[8,9,10]$. Wadah Hussain and Abdul Razzaq Al-Doori (2011) conducted an experiment to study heat transfer by natural convection in a rectangular fin plate with circular perforations as heat sinks [11]. Mohamad I. Al-Widyan and Amjad Al-Shaarawi (2012) studied numerically perforated fins under natural convection. Two geometric parameters, spacing between holes and hole diameter are taken for analysis and it is found that heat transfer from perforated fins increases with Grashof number and also by decreasing spacing between the holes [12]. S. Chamoli, R. Chauhan and N.S.Thakur (2011) worked on Computational Fluid Dynamics (CFD) to examine the heat transfer and friction loss characteristics in a horizontal rectangular channel which is having attachments of circular profile fins over one of its heated surface [13]. O. N. Sara, 
T.Pekdemir, S.Yapici, M.Yilmaz (2001) studied increase in heat transfer and corresponding pressure drop over a flat surface in a channel flow due to perforated rectangular cross-sectional blocks attached on flat surface [14]. Md. Ashiqur Rahman, Taifur Rahman, Md. Hasibul Mahmud and Md. Mahbubul Alam (2005) worked numerically as well as experimentally increased forced heat transfer characteristics from a horizontal flat plate provided by solid and drilled fins of rectangular profile. They found changes in Nusselt number and heat transfer rates due to use of number of equally spaced drilled fins placed at heater surface at different humid condition and a comparison is made with that of equivalent solid fins [15]. M.R. Shaeri, M.Yaghoubi and K Jafarpur (2009) studied numerically three dimensional incompressible laminar fluid flow and heat transfer from an array of solid and perforated fins mounted on a flat plate. Navier Stoke equations and RNG based k- $\varepsilon$ turbulent model is used to predict turbulent flow parameters. SIMPLE algorithm of finite volume method is used to solve conjugate differential equations for gas and solid phase [16, 17]. R. Sam Sukumar, G.Sriharsha, S. Bala Arun, P.Dilip kumar and Ch.Sanyasi Naidu (2013) studied fluid flow and heat transfer characteristics of standard continuous heat sinks of different designs through Computational Fluid Dynamics to determine heat sink which is most excellent for efficient cooling of electronic devices [18]. Bayram Sahin and Alparslan Demir (2008) studied increase in heat transfer and pressure drop over a flat surface provided eith square and circular cross-sectional perforated pin fins in a rectangular channel. Results obtained shows that there is an increase in turbulence of flow in longer fins resulting in an increase in heat transfer and also there is an enhancement in heat transfer with perforated fins higher than that of solid fins [19, 20]. R.B. Gurav, J.D. Patil, S.M. Gaikwad, Pritee Purohit and A.A. Ramgude (2013) studies heat transfer augmentation from a horizontal rectangular fin embedded with elliptical perforation under natural convection compared to nonperforated fin using finite volume method [21]. Rupali V. Dhanadhya, Abhay S. Nilawar and Yogesh L. Yenarkar (2013) studies augmentation of heat transfer from horizontal rectangular fin with circular perforations under natural convection compared with solid fin [22].

\section{Materials and Methodology}

In this paper Ansys 13.0 is used for the simulation work. Modeling has been done using a duct of 200 $\mathrm{mm}$ X $80 \mathrm{~mm}$ cross sectional area with $280 \mathrm{~mm}$ test length. A total of 8 fins are created with $6 \mathrm{~mm}$ thickness. Fins are equally spaced at a distance of $20 \mathrm{~mm}$. Fins have dimension of $120 \mathrm{~mm} \mathrm{X} 60 \mathrm{~mm}$. Base of fins have provided two rectangular cut with $20 \mathrm{~mm}$ height and varying width so that hydraulic depth of rectangular cut can be varied. Heat flux of 200 Watt is provided in the base region of fins.

Analysis of fins has been simulated for various Reynolds number. Material used for both fins and base plate has been taken to be Aluminum. Rectangular cut pattern has been shown in Fig 1 .

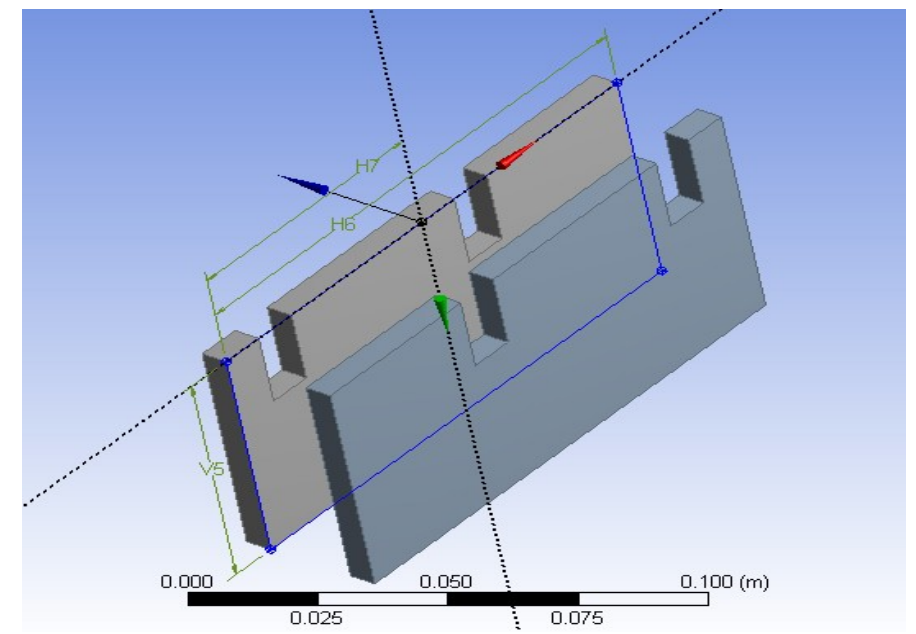

Figure 1: Rectangular cut pattern at the base of the fins

Automatic method is used for the meshing of the geometry. For the accuracy of the simulation work maximum size of the elements has been kept as $6 \mathrm{~mm}$. Total number of elements in mesh generated were approximately $222500-222700$ depending on size of cut. Boundary used as a wall of the duct, Flux area inlet and outlet. Walls are used as an adiabatic wall, at inlet velocity of air is given using various Reynolds number. Outlet is kept as a pressure outlet. SIMPLE algorithm is applied for the calculation of pressure-velocity coupling. Moment and energy equation are solved using second order upwind scheme. Overall arrangement of fins with test duct is shown in Fig 2. 


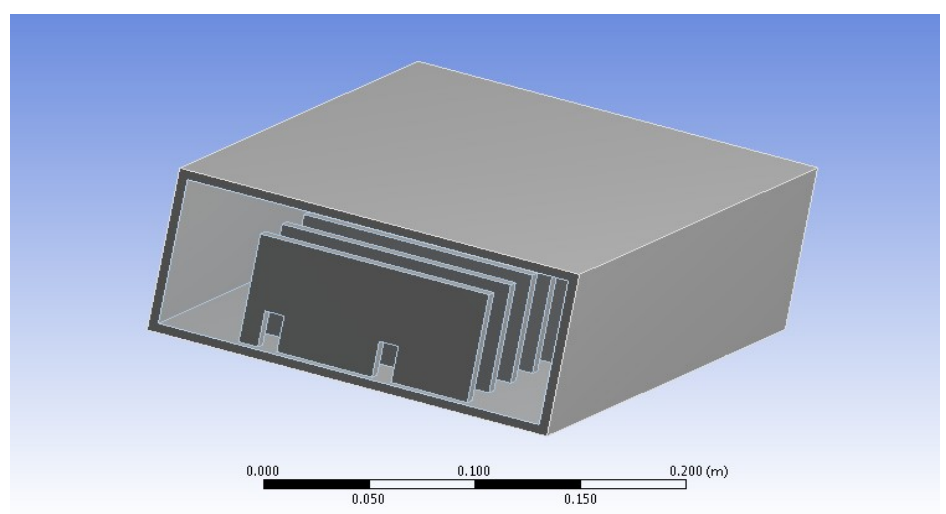

Figure 2: Overall arrangement of fins with test duct

\section{Data Processing}

Heat transfer from a fin can be evaluated using given differential formula:

$\mathrm{d}^{2} \mathrm{~T} / \mathrm{dx}^{2}-\left(\mathrm{hP} / \mathrm{kA}_{\mathrm{c}}\right)\left(\mathrm{T}-\mathrm{T}_{\infty}\right)=0$

Output temperature $\mathrm{T}_{\text {out }}$ is calculated using area weighted average at the outlet of test duct. Total heat transfer is based on convection, conduction and radiation.

Heat transfer through radiation is neglected [1].

Heat transfer through convection can be expressed as:

$\mathrm{Q}_{\text {conv. }}=\mathrm{h}_{\mathrm{av}} \mathrm{A}_{\mathrm{s}}\left[\mathrm{T}_{\mathrm{s}}-\left(\mathrm{T}_{\text {out }}+\mathrm{T}_{\text {in }}\right) / 2\right]$

Where $h_{a v}$ is the average heat transfer coefficient for fin and duct arrangement and $A_{s}$ is the surface area which comes in contact with fluid

Heat transfer through convection will be equal to the heat flux $\mathrm{Q}_{\text {flux }}$ supplied from the bottom of the fin base:

$\mathrm{Q}_{\text {convection }}=\mathrm{Q}_{\text {flux }}$

Using equation (2) and (3) value of $h_{a v}$ can be evaluated. Nusselt number $N_{u}$ based on $h_{a v}$ and hydraulic depth can be deduced as:

$\mathrm{N}_{\mathrm{u}}=\mathrm{h}_{\mathrm{av}} \mathrm{L}_{\mathrm{c}} / \mathrm{K}$

Where $\mathrm{L}_{\mathrm{c}}$ is hydraulic depth and $\mathrm{K}$ is the thermal conductivity of air at average temperature.

Reynold number $\mathrm{R}_{\mathrm{e}}$ is based on test duct inlet cross sectional area can be expressed as:

$\mathrm{R}_{\mathrm{e}}=\rho \mathrm{vD} / \mu$

(5)

Where $\rho$ and $\mu$ are density and viscosity of air and D is hydraulic diameter of test duct. D used in formula can be taken from Table 1.

General momentum equation and energy equation for the simulation are given as:

$\mathrm{X}$ - Momentum equation:

$\rho \frac{D u}{D t}=\frac{\partial \rho u}{\partial t}+\operatorname{div}(\rho \mathbf{U})$

Energy equation:

$\rho_{D t}^{D E}=\frac{\partial \rho E}{\partial t}+\operatorname{div}(\rho E \mathbf{U})$

Table 1: Various flow conditions and geometry of fin array studied

\begin{tabular}{|c|c|c|c|}
\hline $\begin{array}{c}\text { Reynold } \\
\text { number }\end{array}$ & $\begin{array}{c}\text { Height of rectangular } \\
\text { cut(mm) }\end{array}$ & $\begin{array}{c}\text { Width of single } \\
\text { rectangular cut }(\mathrm{mm}) / 2\end{array}$ & $\begin{array}{c}\text { Hydraulic Diameter Of } \\
\text { cut/2 }\end{array}$ \\
\hline \multirow{3}{*}{10000} & 20 & 10 & 13.33 \\
\cline { 2 - 4 } & 20 & 20 & 20.00 \\
\cline { 2 - 4 } & 20 & 30 & 24.00 \\
\cline { 2 - 4 } & 20 & 40 & 26.67 \\
\hline \multirow{3}{*}{20000} & 20 & 10 & 13.33 \\
\cline { 2 - 4 } & 20 & 20 & 20.00 \\
\cline { 2 - 4 } & 20 & 30 & 24.00 \\
\hline \multirow{3}{*}{40000} & 20 & 40 & 26.67 \\
\cline { 2 - 4 } & 20 & 10 & 13.33 \\
\cline { 2 - 4 } & 20 & 20 & 20.00 \\
\cline { 2 - 4 } & 20 & 30 & 24.00 \\
\hline
\end{tabular}

\section{Results and Discussions}

At the steady state, heat flux supplied to the fin arrangement is carried away by convection through fin surface and base plate is exposed to the air. At high flow rate temperature increase in the outlet air is less but the maximum temperature at the fin tip is reduced. When the hydraulic length of rectangular cut is increased more 
base plate area is exposed to the air and turbulence is provided in the vicinity of base plate causing more heat transfer rate. Turbulence created by making hole is more in the case of smaller hydraulic depth of rectangular cut because of the more zigzag motion of the air. This causes the enhancement in Nusselt number. Also due to smaller cut more contact is provided between fins and base plate which adds up the heat transfer coefficient and thus Nusselt number. This increase in Nusselt number can be verified from Fig. 4. Fig. 4 also suggests that there is a Reynold number which corresponds to either maximum Nusselt number or approximately linear relation between them. From Fig. 3 it is evident that depending on the flow rate average value of heat transfer coefficient also changes. In Fig. 5 streamline flow is plotted which shows that even after passing through the rectangular cut air passes by the corner after some time which reduces the heat transfer rate which is expected. In Fig. 3 graph has been plotted for Nusselt number and duct hydraulic depth. From the figure it is evident that for higher Reynold number value of Nusselt number also increases but as the Hydraulic depth increases Nusselt number decreases.

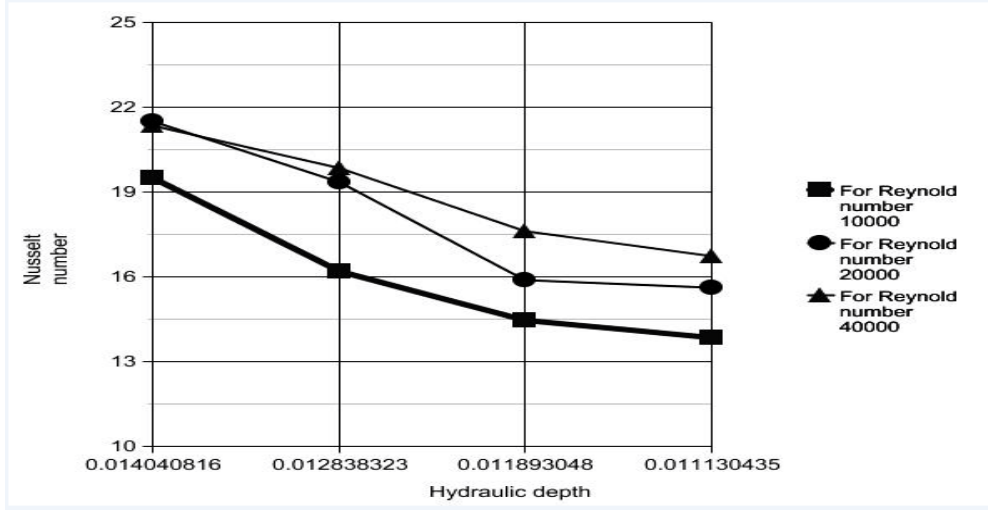

Figure 3: Variation of Nusselt number with hydraulic depth

From fig. 4 it is observed that there is no change in Nusselt number after a particular Reynold number for a given hydraulic cut. It is also observed from the figure that there is drastic increase in Nusselt number after a particular hydraulic diameter of cut. Also below a particular diameter of cut there is optimum value of Nusselt number corresponding to Reynold number. From figure it is observed that for Reynold number equal to 20000, trend for Nusselt number reaches to optimum after a particular hydraulic diameter of cut.

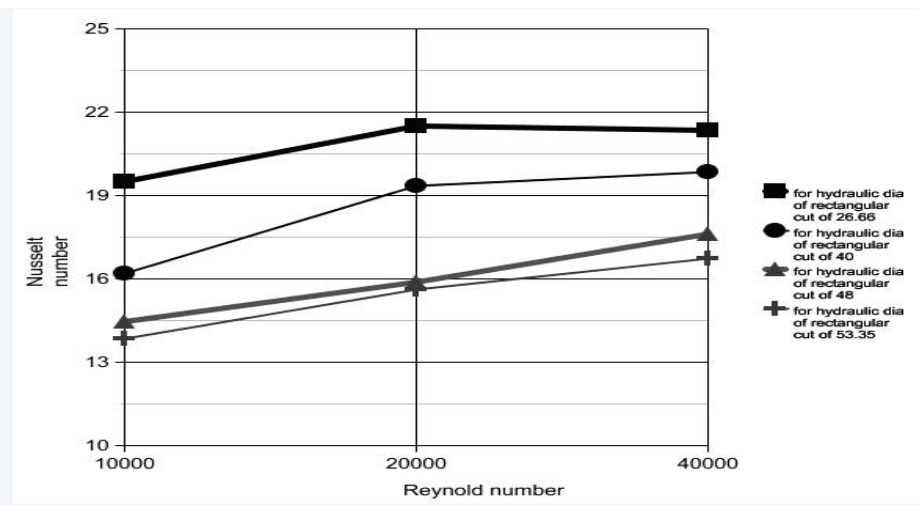

Figure 4: Variation of Nusselt number with Reynold number for different values of hydraulic diameter of rectangular cut 


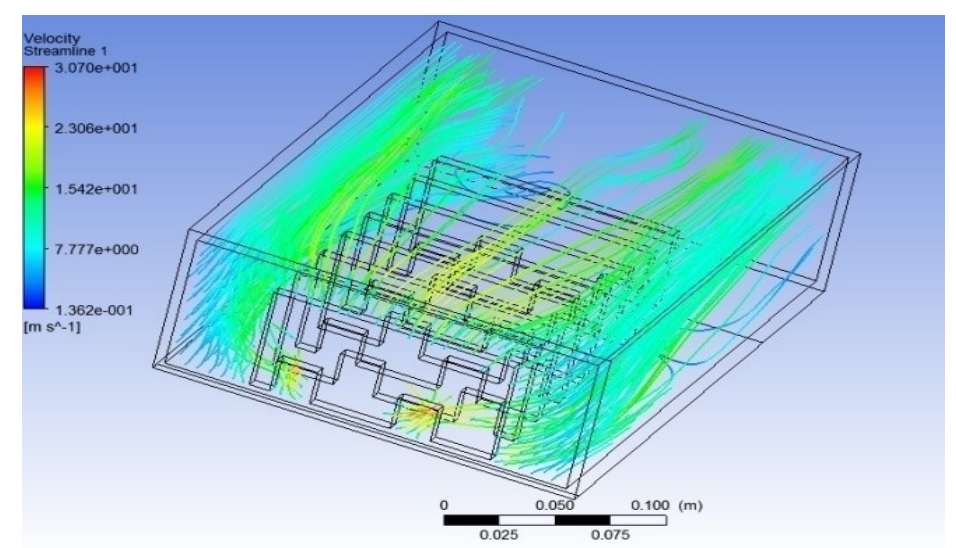

Figure 5: Streamline flow through fin arrangement

\section{Conclusion}

Results obtained from the simulation shows some useful output.

1. Nusselt number is maximum at a specific Reynold number for a particular hydraulic depth of rectangular cut.

2. Nusselt number is more for higher flow rate as compared to low Reynold number.

3. As the hydraulic depth increases value of Nusselt number decreases.

4. For a specific Reynold number Nusselt number obtains an optimum value corresponding to the hydraulic diameter.

5. Nusselt number becomes almost constant after a particular Reynold number for lower hydraulic diameter of cut.

\section{References:}

[1]. Kavita H. Dhanawade, Vivek K. Sunnapwar and Hanamant S. Dhanawade "Thermal Analysis of Square and Circular Perforated fin Arrays by Forced Convection" International Journal of Cultural Engineering and Technology, 2, February 2014, pp.109-114

[2]. Kavita H. Dhanawade, Vivek K. Sunnapwar, and Hanamant S. Dhanawade "Optimization of Design Parameters for Lateral Circular Perforated Fin Arrays under Forced Convection" Heat Transfer Asian Research, 00(0), 2014, pp 1-16

[3]. B. V. S. S. S. Prasad \& A. V. S. S. K. S. Gupta "Note on the Performance of an Optimal Straight Rectangular Fin with a Semicircular Cut at the Tip" Heat Transfer Engineering, 19:1 , 1998, 53-58

[4]. U. Akyol and K. Bilen, "Heat transfer and thermal performance analysis of a surface with hollow rectangular fins" Applied Thermal Engineering, 26, 2006, pp. 209-216.

[5]. N. Souidi, A. Bontemps, Countercurrent gas- liquid flow in plate -fin heat exchangers with plain and perforated fins"International Journal of Heat and Fluid Flow, 22 , 2001, pp. 450-459.

[6]. Abdullah H. M. AlEssa "One Dimensional finite element heat transfer solution of a fin with triangular perforations of bases parallel and towered its base" Arch Applied Mech. Springer, 79, 2008, pp. 741-751.

[7]. D. Abdullah H. AlEssa "Augmentation of Heat Transfer of a Fin by Rectangular Perforations with Aspect Ratio of Three" International Journal of Mechanics and Applications, 2(1), 2012, pp. 7-11.

[8]. A. H. AlEssa, Ayman M.Maqableh and Shatha Ammourah, "Enhancement of natural convection heat transfer from a fin by rectangular perforations with aspect ratio of two", International journal of Physical Sciences, 4, 2009 , pp. 540-547

[9]. A. H. AlEssa and Mohammed Q. Al-Odat, "Enhancement of natural convection heat transfer from a fin by triangular perforations of bases parallel and toward its base" The Arabian Journal for Science and Engineering, 34 ,2B, 2009, pp. 531-544.

[10]. A. H. AlEssa and Mohmmed I. Al-Widyan, "Enhancement of natural convection heat transfer from a fin by triangular perforations of bases parallel and toward its tip", Applied Mathematics and Mechanics, 29, 2008, pp .1033-1044.

[11]. Wadah Hussain and Abdul Razzaq Al-Doori, "Enhancement of Natural Convection Heat Transfer from Rectangular Fins by Circular Perforations" International Journal of Automotive and Mechanical Engineering, 4, 2011, pp. 428-436

[12]. Mohamad I. Al-Widyan and Amjad Al-Shaarawi, "Numerical investigation of heat transfer enhancement for a perforated fins in natural convection", International Journal of Engineering Research and Applications, 2, 2012, pp. 175-184.

[13]. S. Chamoli, R. Chauhan and N.S. Thakur, "Numerical analysis of heat transfer and thermal performance analysis of surface with circular profile fins", International journal of energy science, 1, 2011, pp. 11-18.

[14]. O. N. Sara, T. Pekdemir, S.Yapici, M.Yilmaz, "Heat transfer enhancement in a channel flow with perforated rectangular blocks", International Journal of Heat and Fluid Flow, 22, 2001, pp. 509-518.

[15]. Md. Ashiqur Rahman, Taifur Rahman, Md. Hasibul Mahmud and Md. Mahbubul Alam, "Study of enhanced forced convection heat transfer from a flat plate by solid and drilled fins under different relative humidity condition", Proceedings of the International Conference on Mechanical Engineering, Dhaka, Bangladesh, 2005, pp. 1-5.

[16]. M.R. Shaeri and M.Yaghoubi,“Thermal enhancement from heat sinks by using perforated fins”, Energy conversion and Management,50, Elsevier 2009 pp. 1264-1270.

[17]. M.R. Shaeri, M.yYaghoubi Numerical analysis of turbulent convection heat transfer from an array of perforated fins, International Journal of Heat and Fluid Flow, 30 , 2009, pp. 218-228.

[18]. R. Sam Sukumar, G.Sriharsha, S. Bala Arun, P.Dilip kumar and Ch.Sanyasi Naidu, "Modelling and Analysis of Heat Sink with Rectangular Fins Having Through Holes" International Journal of Engineering Research and Applications, 3, April 2013, pp. $1557-1561$

[19]. Bayram Sahin and Alparslan Demir, "Performance analysis of a heat exchanger having perforated square fins", Applied Thermal Engineering, 28, 2008, pp. 621-632. 
[20]. Bayram Sahin and Alparslan Demir, "Thermal performance analysis and optimum design parameters of heat exchanger having perforated pin fins", Energy Conversion and Management, 49, 2008, pp.1684-1695.

[21]. R.B. Gurav, J.D. Patil, S.M. Gaikwad, Pritee Purohit and A.A.Ramgude, "Finite Volume Analysis of Convective Heat Transfer Augmentation from Horizontal Rectangular Fin by Elliptical Perforations", International Journal of Global Technology Initiatives, 2013, RIZVI, Bandra

[22]. Rupali V. Dhanadhya, Abhay S. Nilawar and Yogesh L. Yenarkar, "Theoretical Study and Finite Element Analysis of Convective Heat Transfer Augmentation from Horizontal Rectangular Fin with Circular Perforation", International Journal of Mechanical and Production Engineering Research and Development, 3, June 2013, pp. 187-192

[23]. D. G. Kumbhar, Dr. N.K. Sane and S.T. Chavan "Finite Element Analysis and Experimental Study of Convective Heat Transfer Augmentation from Horizontal Rectangular Fin by Triangular Perforations", Proc. of the International Conference on Advances in Mechanical Engineering, August 2009, SVNIT Surat.

[24]. Frank P. Incropera and David P. DeWitt , Fundamentals of Heat and Mass Transfer , New Delhi, Tata Mcgraw Hill, Fourth Edition

[25]. J P Holman and Souvik Bhattacharyya, Heat Transfer New Delhi, Tata Mcgraw Hill, Tenth Edition 